\title{
How Precalculus Course Coordination Can Impact Students' Academic Performance
}

\author{
Amir H. Golnabi \\ Phillips Exeter Academy \\ Eileen Murray \\ Math for America \\ Haiyan Su \\ Montclair State University
}

\begin{abstract}
This study aims to measure the impact of course coordination and instructor support to implement a research-based curriculum on students' academic performance. Our results confirm that a careful curriculum design in addition to a dedicated course coordination can have a positive impact on students' learning. A reflective teaching philosophy and opportunity to engage in critical conversations about teaching and learning promoted through course coordination can influence classroom practice and result in improved student outcomes. We recommend that departments should recognize the importance of course coordination and encourage faculty to work closely towards the common aim of delivering the best teaching practices.
\end{abstract}

Keywords: course coordination, precalculus, student achievement, part-time instructors, course design, assessment, STEM

\section{MOTIVATION}

Educational research studies have indicated that the level of interest towards Science, Technology, Engineering, and Mathematics (STEM) has declined both in terms of enrollment (Sjøberg \& Schreiner, 2007) and student motivation to learn science (Osborne et al, 2003). This problem has been especially concerning in western countries and more prosperous Asian nations (Thomas \& Watters, 2015). Despite the strong labor-market demand for STEM, these fields still attract a smaller share of students (OECD, 2019). In the United States, the number of students in STEM fields has remained constant while the demand for STEM majors has been increasing (Carnevale et al, 2011). In the coming years, approximately one million STEM graduates are expected to be needed to meet the economic demands of the U.S. workforce (President's Council, 2012). This trend points towards the need for research on attracting and retaining STEM students in higher education. Existing research shows that students' classroom and learning experiences can influence their decisions to pursue STEM degrees, especially initial experiences in introductory mathematics courses (Pampaka et al, 2012). Students often blame poor instruction as a cause 
for leaving science majors (Seymour \& Hewitt, 1997). Therefore, improving instruction may influence their decision to stay in STEM (Ellis et al, 2014).

\section{METHODS}

\section{Background}

This paper presents work from a larger project, Adjunct Mathematics Instructor Resources and Support: Improving Undergraduate Precalculus Teaching and Learning Experience (Project AMIRS). This project aims to measure the impact of course coordination and support on part-time Precalculus instructors' knowledge, instructional practices, and job satisfaction as well as students' academic success and retention in STEM majors. We use coordination of Precalculus to further the goals of implementing best practices for learning and instruction, improving content and pedagogical content knowledge of instructors, creating a professional learning community, and improving student academic achievement. In this paper, we present our findings regarding one of our project's research questions on how course coordination and adjunct instructor support impact student academic performance.

\section{Context}

In the Department of Mathematical Sciences at Montclair State University, part-time, or adjunct, faculty members have taught the majority of the Precalculus sections. Historically, there had been no coordination of these sections, and thus a great deal of inconsistency emerged in how the course had been taught. To address this issue, in Fall 2016 the department assigned a full-time faculty member as the course coordinator for the 4-credit introductory Precalculus course which is required by all STEM majors who are placed in the course through placement exam. This semester was also the first in which the newly adopted researchbased curriculum, Precalculus: Pathways to Calculus (Pathways; Carlson et al, 2010), was implemented. Situtated within Project AMIRS, the course coordinator (second author), with support from the research team, began to provide a variety of supports such as a common syllabus, pacing guide, and assessments in addition to access to the designated course coordinator, as well as workshops and professional learning opportunities to help instructors implement the curriculum.

The department also supports two different 4-credit first-courses in Calculus. All science majors are required to take "Calculus I," with the exception of Biology and Information Technology (IT). Biology and IT students take "Calculus A," which is an equivalent course that is specifically designed for life science majors. The primary learning goal of Calculus A is to acquire the ability to understand the importance of the mathematical concepts in calculus and apply them to solve problems in life sciences. This course is particularly important and challenging since students are not required to take any additional mathematics courses. Unlike Calculus I but similar to Precalculus, Calculus A is mainly taught by part-time instructors. Moreover, Calculus A is a coordinated course with a common syllabus, pacing, project, and final exam, in addition to access to a designated course coordinator (first author).

\section{Participants and Data Collection}

The participants in our study were students who took Precalculus in the department during either Fall or Spring semester between Fall 2015 and Spring 2018 (6 cohorts). A student entered a cohort when they took the Precalculus course in the department for the first time. We report on I) academic achievement, II) retention, and III) departmental assessment reports, described below. Achievement and retention data were provided by the university's Office of Institutional Research which is housed within the Office of Information Technology.

Student academic achievement was measured by students' Precalculus and corresponding subsequent Calculus grades over 6 semesters from Fall 2015 to Spring 2018. In particular, we analyzed this data from students who passed Precalculus the same semester they entered the cohort and took the subsequent Calculus course over the immediate following semester (Fall or Spring). The grades were classified in one of the following three categories: 1) Pass, $P(>70 \%)$; 2) Fail ${ }^{1}, F(<70 \%)$; or 3) Withdrawn, $W$. We refer to these as the $\mathrm{P} / \mathrm{F} / \mathrm{W}$ categories. 
Retention refers to retaining students in STEM education (within the College of Science and Mathematics) during their academic careers, for instance from the freshman to sophomore year.

Departmental Assessment Reports refers to a written record of the departmental assessment plan that was initially developed by a committee of five department members in 2005 . The assessment plan was originally created for accreditation purposes. However, its purpose and use evolved over time and became an analysis tool to provide a detailed picture of students' performance towards overarching departmental program learning goals. The program learning goals (PLGs) and assessment questions were revised and adjusted over the years by the department assessment committee. The following program learning goals (PLGs) were assessed for the courses presented in this work:

- PLG1: Students master the fundamentals of their disciplines and be conversant in the language of mathematics.

- PLG2: Students master multi-step problems.

- PLG3: Students think beyond algorithms and formulas to a greater emphasis on analytical and critical thinking associated with the underlying concepts and applications of their discipline.

In addition, for each assessed course and measurable outcome, an instructor-independent rubric was designed with the following scoring criteria:

- 1 and 2: Does Not Meet Expectations

- 3 and 4: Meets Expectations

- 5: Exceeds Expectations. (Note: It is expected that this score (exceptional or excellent) will be a rare event.)

Each assessed course was evaluated by at least two people, the course instructor and at least one other department member. The scoring criteria was negotiated between the evaluators for each assessment item for consistency. The assessment committee and course evaluators reviewed, summarized, and prepared a written report each semester which was then presented to the entire department. A number of introductory mathematics courses including Precalculus, Calculus I, Calculus A, and Calculus II were evaluated in the department on a regular basis as part of this assessment plan. For the purposes of this study, we limit our focus to the Calculus I reports to specifically investigate outcomes in that course ${ }^{2}$.

\section{Data Analysis}

For the purposes of this study, pre-coordination refers to the two cohorts (Fall 2015 and Spring 2016) before the adoption of Pathways, where instructors did not receive any formal training or support for course coordination. Correspondingly, post-coordination refers to the four cohorts (Fall 2016 to Spring 2018) after the adoption of Pathways, where instructors received formal training and support from course coordination through the department. We compared the Precalculus and Calculus passing rates as well as retention rates between the pre- and post-coordination cohorts using the Chi-square test.

We also used the Chi-square test to compare the percentage of PLGs that were met or exceeded expectations by students taking Calculus I pre- and post-coordination. In addition, we used the same statistical test to compare 4 post-coordination semesters (FA16, FA17, FA18 and FA19) of assessment report data for Calculus I. Finally, to test our hypothesis about grading variability among different Calculus I instructors, we used the Chi-square test to compare the passing rates of students during 3 post-coordination semesters (FA17, FA18, and FA19). All the statistical analyses were conducted in statistical software R (Team, R. C., 2017).

\section{RESULTS}

\section{Student Achievement in Precalculus}

The analysis result of students' achievement in Precalculus using the P/F/W categories by comparing student pass rates along with the corresponding standard errors (SE) before and after the start of Project AMIRS is given in Table 1. Two cohorts $(\mathrm{N}=587)$ were included in the pre-coordination and four cohorts $(\mathrm{N}=1,131)$ were included in the post-coordination. The passing rate $(71.53 \%)$ was slightly higher in the 
post-coordination cohorts. However, this difference was not statistically significant from the passing rate $(70.70 \%)$ of the cohorts in pre-coordination with p-value 0.7605 .

TABLE 1

PRECALCULUS AND CALCULUS PASSING RATE ALONG WITH THE CORRESPONDING STANDARD ERROR (SE) COMPARISON BETWEEN PRE- AND POST-COORDINATION

\begin{tabular}{|c|c|c|c|c|}
\hline \multirow{2}{*}{$\begin{array}{c}\text { Final } \\
\text { Grade }\end{array}$} & $\begin{array}{c}\text { Pre-coordination } \\
\text { Count (\%, SE) }\end{array}$ & $\begin{array}{c}\text { Post-coordination } \\
\text { Count (\%, SE) }\end{array}$ & $\begin{array}{c}\text { Pre-coordination } \\
\text { Count (\%, SE) }\end{array}$ & $\begin{array}{c}\text { Post-coordination } \\
\text { Count (\%, SE) }\end{array}$ \\
\hline P & $415(70.70 \%, 1.88 \%)$ & $809(71.53 \%, 1.34 \%)$ & $192(66.90 \%, 2.78 \%)$ & $346(65.25 \%, 2.07 \%)$ \\
\hline F & $124(21.12 \%, 1.68 \%)$ & $230(20.34 \%, 1.20 \%)$ & $72(25.09 \%, 2.56 \%)$ & $148(28.08 \%, 1.96 \%)$ \\
\hline W & $48(8.18 \%, 1.13 \%)$ & $92(8.13 \%, 0.81 \%)$ & $23(8.01 \%, 1.60 \%)$ & $33(6.26 \%, 1.06 \%)$ \\
\hline Total & $587(100 \%)$ & $1131(100 \%)$ & $287(100 \%)$ & $527(100 \%)$ \\
\hline
\end{tabular}

Student Achievement From Precalculus to Calculus

We also compared the passing rate of all calculus sections (Calculus I \& Calculus A) between the preand post-coordination cohorts: 287 out of 415 students who passed Precalculus took calculus during the immediate following semester in the pre-coordination cohorts; 527 out of 809 students who passed Precalculus took calculus during the immediate following semester. These students were included in the comparison of calculus passing rate. Table 1 shows there was no significant difference between the passing rates $(66.90 \%$ vs $65.25 \%$, p-value 0.7789$)$ of calculus sections combined (I \& A) in the pre- and postcoordination cohorts.

\section{Calculus I vs. Calculus A}

Since students who take Calculus I and Calculus A come from different populations and the two courses are run differently, we analyzed students' performance separately in Calculus I and Calculus A by looking at their pass rates $(>70 \%)$ both pre- and post-coordination. By analyzing the aggregate data from two cohorts who took Calculus I during the immediate following semester passing Precalculus before coordination $(\mathrm{N}=148)$ and 4 cohorts after coordination $(\mathrm{N}=253)$, we observed the Calculus I passing rate was statistically significantly lower $(\mathrm{p}$-value $=0.0137)$ in post-coordination cohorts, and the failing rate was significantly higher in post-coordination cohorts. On the other hand, Calculus A passing rate was statistically significantly higher $(81.75 \%$ vs $72.66 \%$, p-value $=0.045)$ after Precalculus coordination (See Table 2).

TABLE 2

CALCULUS I AND A PASSING RATE ALONG WITH THE CORRESPONDING STANDARD ERROR (SE) COMPARISON BETWEEN PRE- AND POST-COORDINATION COHORTS

\begin{tabular}{|c|c|c|c|c|c|c|}
\hline \multirow[b]{2}{*}{$\begin{array}{l}\text { Final } \\
\text { Grade }\end{array}$} & \multicolumn{3}{|c|}{ Calculus I } & \multicolumn{3}{|c|}{ Calculus A } \\
\hline & $\begin{array}{c}\text { Pre- } \\
\text { coordination } \\
\text { Count } \\
(\%, \text { SE })\end{array}$ & $\begin{array}{c}\text { Post- } \\
\text { coordination } \\
\text { Count } \\
(\%, \text { SE })\end{array}$ & $\begin{array}{l}\text { Chi- } \\
\text { square } \\
\text { test (p- } \\
\text { value) }\end{array}$ & $\begin{array}{c}\text { Pre- } \\
\text { coordination } \\
\text { Count } \\
(\%, S E)\end{array}$ & $\begin{array}{c}\text { Post- } \\
\text { coordination } \\
\text { Count } \\
(\%, \text { SE })\end{array}$ & $\begin{array}{l}\text { Chi- } \\
\text { square } \\
\text { test (p- } \\
\text { value) }\end{array}$ \\
\hline $\mathrm{P}$ & $\begin{array}{c}91 \\
(61.49 \% \\
4.00 \%) \\
\end{array}$ & $\begin{array}{c}122 \\
(48.22 \%, \\
3.14 \%) \\
\end{array}$ & 0.0137 & $\begin{array}{c}101 \\
(72.66 \%, \\
3.78 \%) \\
\end{array}$ & $\begin{array}{c}224 \\
(81.75 \%, \\
2.33 \%) \\
\end{array}$ & 0.045 \\
\hline $\mathrm{F}$ & $\begin{array}{c}42 \\
(28.38 \% \\
3.71 \%)\end{array}$ & $\begin{array}{c}103 \\
(40.71 \% \\
3.08 \%)\end{array}$ & 0.0177 & $\begin{array}{c}30 \\
(21.58 \% \\
3.49 \%)\end{array}$ & $\begin{array}{c}45 \\
(16.42 \% \\
2.24 \%) \\
\end{array}$ & 0.2501 \\
\hline
\end{tabular}




\begin{tabular}{|c|c|c|c|c|c|c|}
\hline \multirow{2}{*}{$\mathrm{W}$} & 15 & 28 & & 8 & 5 & \\
& $(10.14 \%$, & $(11.07 \%$, & 0.9014 & $(5.76 \%$, & $(1.82 \%$, & 0.0624 \\
& $2.48 \%)$ & $1.97 \%)$ & & $1.98 \%)$ & $0.81 \%)$ & \\
\hline \multirow{2}{*}{ Total } & 148 & 253 & & 139 & 274 & \\
& $(100 \%)$ & $(100 \%)$ & & $(100 \%)$ & $(100 \%)$ & \\
\hline
\end{tabular}

We also compared the passing rate between Calculus I and Calculus A in the pre- and post-coordination cohorts. In the pre-coordination cohorts, Calculus I passing rate $(61.49 \%)$ and Calculus A passing rate $(72.66 \%)$ were near statistical significance at 5\% (p-value 0.059). Calculus I and Calculus A had significantly different passing rates $(48.22 \%$ vs $81.75 \%)$ in post-coordination cohorts with p-value of 0 .

\section{A Closer Look at Calculus I}

Assessment Report Comparison Pre- and Post-Coordination

After isolating particular learning goals and comparing assessment reports for pre- and postcoordination, we observed there was significant difference in the "meet or exceed expectations" rates. The post-coordination assessment reports had significantly higher rates of meeting all three learning goals with 1-sided p-value of 0, 0.0373, and 0.0004, for PLG1, PLG2 and PLG3 respectively (see Table 3).

In order to study the impact of the precalculus course redesign and coordination on students' performance in Calculus $\mathrm{I}^{2}$, we also compared the three PLGs "meet or exceed expectations" rates for three fall semesters among post-coordination because of the timing of the assessment reports (see Table 4). We observed that there was no significant difference in the "meet or exceed expectations" rates of PLG1 among post-coordination semesters (p-value 0.1404). However, there were significant differences in the rates of PLG2 and PLG3 during post-coordination with p-values 0.0024 and 0.0053 , respectively. Specifically, the "meet or exceed expectations" rates of PLG2 and PLG3 during FA17 were significantly lower than those in FA18 and FA19, while the "meet or exceed expectations" rates in FA18 and FA19 were not significantly different from each other.

TABLE 3

PROGRAM LEARNING GOALS (PLGS) MEETING OR EXCEEDING EXPECTATIONS RATE ALONG WITH THE CORRESPONDING STANDARD ERROR (SE) COMPARISON BETWEEN PRE- AND POST-COORDINATION FOR CALCULUS I

\begin{tabular}{|c|c|c|c|}
\hline \multirow{2}{*}{ PLG } & \multicolumn{3}{|c|}{ Calculus I } \\
\cline { 2 - 4 } & $\begin{array}{c}\text { Pre-coordination Count } \\
(\%, \text { SE) }\end{array}$ & $\begin{array}{c}\text { Post-coordination Count } \\
(\%, \mathbf{S E})\end{array}$ & $\begin{array}{c}\text { Chi-square test } \\
\text { (1-sided p-value) }\end{array}$ \\
\hline \multirow{2}{*}{1} & $\begin{array}{c}51 \\
(42.86 \%, 4.54 \%)\end{array}$ & $\begin{array}{c}111 \\
\mathbf{0 . 0 0 0 0}\end{array}$ \\
\hline 2 & 33 & $(73.03 \%, 3.60 \%)$ & $\mathbf{0 . 0 3 7 3}$ \\
\hline 3 & $(27.73 \%, 4.10 \%)$ & $(38.82 \%, 3.95 \%)$ & $\mathbf{0 . 0 0 0 4}$ \\
\hline \multirow{2}{*}{ Total } & 24 & 61 & \\
\hline
\end{tabular}


TABLE 4

PLGS MEETING OR EXCEEDING EXPECTATIONS RATE ALONG WITH THE CORRESPONDING STANDARD ERROR (SE) COMPARISON AMONG POSTCOORDINATION COHORTS (FA17, 18, AND 19) FOR CALCULUS I

\begin{tabular}{|c|c|c|c|c|}
\hline \multirow{2}{*}{ PLG } & \multicolumn{4}{|c|}{ Calculus I } \\
\cline { 2 - 5 } & $\begin{array}{c}\text { FA17 Count } \\
(\%, \mathbf{S E})\end{array}$ & $\begin{array}{c}\text { FA18 Count } \\
(\mathbf{\%}, \mathbf{S E})\end{array}$ & $\begin{array}{c}\text { FA19 Count } \\
(\%, \mathbf{S E})\end{array}$ & $\begin{array}{c}\text { Chi-square } \\
\text { test (2-sided } \\
\text { p-value) }\end{array}$ \\
\hline 1 & $\begin{array}{c}32 \\
(66.67 \%, 6.80 \%)\end{array}$ & $\begin{array}{c}34 \\
(77.27 \%, 6.32 \%)\end{array}$ & $\begin{array}{c}45 \\
(83.33 \%, 5.07 \%)\end{array}$ & 0.1404 \\
\hline 2 & $(20.83 \%, 5.86 \%)$ & $(54.55 \%, 7.51 \%)$ & $(46.30 \%, 6.79 \%)$ & $\mathbf{0 . 0 0 2 4}$ \\
\hline 3 & 11 & $\begin{array}{c}22 \\
22\end{array}$ & $\mathbf{0 . 0 0 5 3}$ \\
\hline Total & $48(100 \%)$ & $44(100 \%)$ & $54(100 \%)$ & \\
\hline
\end{tabular}

Passing Rates Separated by Instructor

After isolating Calculus I passing rates by each instructor, we observed there were significant differences in grading among the eight instructors in all the three post-coordination cohorts FA17, FA18, and FA19 with p-values 0.0115, 0.0071, and 0.0019, respectively (see Table 5). It should be noted that during any of the terms, only four distinct instructors taught the 4-5 sections of Calculus I. Also, for simpler comparison purposes, the instructors were numbered 1-8 based on their class passing rates. (Instructors 68 had passing rates less than $50 \%$.)

TABLE 5

CALCULUS I PASSING RATE ALONG WITH THE CORRESPONDING STANDARD ERROR (SE) COMPARISON BETWEEN 8 DIFFERENT INSTRUCTORS TEACHING POSTCOORDINATION COHORTS (FA17, 18, AND 19)

\begin{tabular}{|c|c|c|c|}
\hline \multirow{2}{*}{ Post- coordination Cohort } & \multicolumn{3}{|c|}{ Calculus I Passing Rate } \\
\cline { 2 - 4 } & FA17 & FA18 & FA19 \\
\hline Instructor 1 Count $(\%, \mathrm{SE})$ & $33(66 \%, 6.70 \%)$ & Did not teach & $19(76 \%, 8.54 \%)$ \\
\hline Instructor 2 Count $(\%, \mathrm{SE})$ & Did not teach & $18(72 \%, 8.98 \%)$ & Did not teach \\
\hline Instructor 3 Count $(\%, \mathrm{SE})$ & $16(64 \%, 9.60 \%)$ & Did not teach & Did not teach \\
\hline Instructor 4 Count $(\%, \mathrm{SE})$ & Did not teach & Did not teach & $18(72 \%, 8.98 \%)$ \\
\hline Instructor 5 Count $(\%, \mathrm{SE})$ & Did not teach & Did not teach & $36(72 \%, 6.35 \%)$ \\
\hline Instructor 6 Count $(\%, \mathrm{SE})$ & $9(36 \%, 9.60 \%)$ & $10(43.48 \%, 10.34 \%)$ & Did not teach \\
\hline Instructor 7 Count $(\%, \mathrm{SE})$ & $9(34.62 \%, 9.32 \%)$ & $10(40 \%, 9.80 \%)$ & Did not teach \\
\hline Instructor 8 Count $(\%, \mathrm{SE})$ & Did not teach & $6(24 \%, 8.54 \%)$ & $8(32 \%, 9.33 \%)$ \\
\hline $\begin{array}{c}\text { Chi-square test } \\
\text { (2-sided p-value) }\end{array}$ & $\mathbf{0 . 0 1 1 5}$ & $\mathbf{0 . 0 0 7 1}$ & $\mathbf{0 . 0 0 1 9}$ \\
\hline
\end{tabular}

\section{Student Retention}

Retention rate was defined as the ratio of the number of students whose initial major was STEM and remained in STEM through the end of the Spring 2018 semester or when they graduated to the number of students whose initial major was STEM. Using a Chi-square test to compare the two retention rates, 359 out of $466(77.04 \%)$ in the pre-coordination cohorts and 410 out of $505(81.19 \%)$ in the post-coordination cohorts, we found they were not significantly different at the level of $5 \%$. 


\section{DISCUSSION}

\section{Course Coordination}

The above results are quite interesting given the fact that similar to our Precalculus curriculum, Calculus A was also a coordinated course with a focus on active learning and conceptual understanding. Students in Calculus A were consistently provided opportunities to connect the subject matter to their interests in real world applications. By doing so, the underlying relationship between apparently disparate areas of science could be illuminated, which offered students a glimpse of a bigger picture. On the other hand, Calculus I sections were typically taught in a lecture format and the level of course coordination was limited to only textbook/content selection.

We conjecture that the course coordination played an important role in Calculus A, especially since the coordinator was also involved with Project AMIRS as a co-principal investigator and the Precalculus course coordination effort. Similar to Precalculus, the coordination of Calculus A included common syllabus and pacing, and common assessments and rubrics amounting to $50 \%$ of the final grade. The part-time faculty who taught Calculus A also had access to the designated coordinator who met with them regularly to discuss

course objectives, pacing, suggested student-centered activities, and other effective pedagogical approaches.

\section{Course Design}

Beyond course coordination, we hypothesize that a focus on course design impacted student achievement. In 2017-18, the two coordinators of Precalculus and Calculus A courses participated in a research academy learning program through which they defined goals, objectives, and curriculum mapping for the course sequence Algebra-Precalculus-Calculus, described below.

\section{Goals}

The overarching goals for the sequence of courses were defined as: (1) students are able to use modeling and problem-solving techniques to solve mathematical problems; and (2) students understand connections between multiple representations of functions (e.g., tables, graphs, equations). These goals were created based on the coordinators' understanding of best practices as well as their alignment with the departmental program learning goals. Specifically, the coordinators saw these two goals as connected to mastering fundamentals and multi-step problems through their abilities to use modeling and problem-solving techniques. Moreover, students' understanding of the connections between multiple representations could support this mastery as well as their development of analytical and critical thinking.

\section{Objectives}

To define the student learning objectives (SLOs), we used each course specific objectives and put an emphasis on the student, used observable action verbs, and created concrete learning statements. For example, the goal to understand connections between multiple representations of functions became the SLO: Students can interpret the rate of change for a function from a graph, table, or equation. The SLOs also helped us align the sequence of courses and plan for common assessments.

\section{Curriculum Mapping}

We created the curriculum mapping (outlined in Table 6) by aligning the SLOs with each course and indicating where each would be introduced (I), reinforced/practiced (R), mastered (M), and summatively assessed (A). This map helped us improve communication with course instructors. We also anticipated that the curriculum mapping could encourage reflective practice as instructors planned for their lessons and assessments. 


\section{TABLE 6 \\ CURRICULUM MAPPING FOR ALGEBRA-PRECALCULUS-CALCULUS COURSE SEQUENCE}

\begin{tabular}{|c|c|c|c|c|}
\hline Course & $\begin{array}{c}\text { SLO1: Algebraic } \\
\text { Processes }\end{array}$ & $\begin{array}{c}\text { SLO2: Relations } \\
\text { \& Functions }\end{array}$ & $\begin{array}{c}\text { SLO3: Rate } \\
\text { of Change }\end{array}$ & $\begin{array}{c}\text { SLO4: Antiderivatives \& } \\
\text { Areas Under a Curve }\end{array}$ \\
\hline Algebra & I R A & I R A & & \\
\hline Precalculus & R M A & R M A & I R A & I R A \\
\hline Calculus & M & M A & R M A & \\
\hline
\end{tabular}

\section{Assessment}

While goal setting enhances the course, assessing whether those goals are reached is crucial. Thus, a variety of assessments should be integrated seamlessly into the entire course. In particular, formative assessments can assure that substantive learning happens at every step of the process. For the coordinated Precalculus and Calculus A courses, we integrated formative assessments into our course structure to foster in-depth understanding of the key concepts and keep both instructors and students in the loop with what is happening in class (Bressoud, Mesa, \& Rasmussen, 2015). In contrast, there was no coordinated effort to infuse formative assessments consistently within the Calculus I sections.

To better understand these discrepancies, we took a closer look at the Calculus I assessment reports that evaluated student proficiency in specific departmental learning goals. Our rationale for this was that these learning goals were aligned with our promoted student-centered teaching philosophy in Precalculus and Calculus A, but were not part of Calculus I in any coordinated manner. Furthermore, by analyzing the departmental assessment reports, we were able to understand student achievement beyond final grades, which are usually determined predominantly by summative assessments (e.g., homework and exam grades).

We found that post-coordination Calculus I assessment reports had significantly higher rates of meeting all three learning goals, meaning that students met/exceeded expectations in all three learning goals in Calculus I independent of their final grades (See Table 3). Looking more closely at the learning goals individually for three fall semesters among post-coordination, we also found significant differences in the rates of PLG2 and PLG3 where students met/exceeded expectations in those two goals during FA18 and FA19 at a significantly higher rate than those in FA17 (See Table 4). These results were intriguing because they indicated that students in post-coordination cohorts were failing Calculus I at significantly higher rates while meeting/exceeding expectations of the course learning goals at significantly higher rates.

To unpack these observations, we separated Calculus I passing rates by each instructor and observed that there were statistically significant differences in grading among them in all the three post-coordination cohorts (Table 5). We believe this passing rate variability is due to the instructor, and not the student population, because of random assignment of students. Therefore, we hypothesize one possible explanation could be the fact that some of these instructors employed more traditional grading/assessment practices that heavily relied on summative assessments. This is a possible explanation because research has shown that summative assessments do not always provide a clear and comprehensive picture of student learning (e.g., Knight, 2002).

Faculty administer summative assessments in order to attain evidence of achievement but what counts as evidence can vary, especially in courses such as Calculus with complex learning goals (Knight, 2002). While some mismatch can be reduced across a multi-section course taught by several instructors through course coordination, there will always be the need for interpretation, negotiation, and clarification of what counts as evidence of achievement. Mathematics faculty are inclined to have confidence in summative assessments because of the belief that determining the level of mastery for concepts and principles in calculus may be more easily quantified in mathematics courses (Lattuca \& Stark, 2009). According to the analysis of exam items from five Calculus I instructors in one department, researchers found statistically significant differences in problem type (White \& Mesa, 2014). In fact, "some faculty required students to demonstrate mastery on a larger share of problems characterized as rich tasks and complex procedures 
while others more often assessed student proficiency with problems characterized as simple procedures" (Bressoud et al, 2013, p. 51). Therefore, to improve Calculus I student achievement, learning, and consistency of experience across sections, we believe mathematics faculty should collaborate around assessment and even engage in professional learning focused on assessment and rubric development (Bressoud et al, 2015). We based this, in part, because we know that mathematics faculty tend to design summative assessments with different cognitive complexity when working alone (Bressoud et al, 2013).

Our student achievement data supports this research, indicating that our calculus students may have been held to different standards depending on the types of problems presented to them in their particular section. Thus, we believe that the department would benefit from the type of course coordination that we applied for Precalculus and Calculus A. By reviewing sample syllabi for Calculus I, departmental meeting minutes, and the Calculus I assessment reports, we found that Calculus I final grades were determined heavily based on summative assessments (quizzes, midterms, and final) and homework, whereas in Precalculus and Calculus A additional components associated with participation and formative assessments were taken into account. Moreover, in reviewing these documents, we saw how the department full-time faculty had been reorganizing the content of Calculus I, Calculus II and Calculus III since 2014. The meetings associated with this reorganization seemed to focus on reviewing previous assessment reports in order to monitor students' ongoing progress. This monitoring was used to ensure that the Calculus course sequence utilized most appropriate course materials (e.g., textbooks, technology) and maintained optimal content organization. However, there was not any coordination around best instructional practices or the use of assessment.

Beginning in Fall 2018, Calculus instructors met monthly to also think about how to change parts of the curriculum with the goal of improving student outcomes. The Calculus coordinator attempted to align this work with the curriculum mapping for Algebra-Precalculus-Calculus course sequence that was being used for Precalculus and Calculus A. However, it is unclear how much this mapping was discussed and what ways it informed instructional and assessment practices of the Calculus I instructors. One clear result of these meetings was that in Fall 2019, the department decided on a new textbook, a change that seemed to be motivated more by the desire to use an open-source textbook. According to the Fall 2019 assessment report, the Calculus coordinator was hopeful that by adopting the new text and engaging in conversations with the instructors about the number of sections covered in each class, students learning would also benefit. However, we were unable to find any documentation regarding coordination that included the types of activities that Precalculus and Calculus A instructors took part, including discussions about pedagogical approaches that incorporated formative assessment, student-centered activities, as well as common summative assessments and rubrics.

Strong course coordination that supports shared summative assessment practices in addition to pedagogical approaches that incorporate formative assessment could mitigate the observed passing rate variability by providing multiple avenues to assess student learning, align instructor and department expectations, and provide a clear pathway for students to achieve educational goals and success. However, it is important to note that in the case of Precalculus and Calculus A, the nature of part-time instructor positions (in contrast to full-time faculty) may have played an important role in accepting and adapting to coordination efforts.

\section{CONCLUSION}

Our results suggest that a careful curriculum design in addition to a dedicated course coordination can have a significant positive impact on students' learning and their academic performance. In particular, we observed that the reflective teaching philosophy and opportunity to engage instructors in critical conversations about teaching and learning influenced classroom practice and resulted in improved student outcomes. Based on our research, we recommend the following three actions in Precalculus and Calculus courses: 


\begin{abstract}
Aligning Course Design
Learning objectives, course structure/components, and assessment (both formative and summative) should be aligned so that students are regularly expected to apply knowledge, make interpretations, and provide explanations related to the key concepts. We strongly believe that emphasis on conceptual understanding and problem-solving over algebraic manipulation in Precalculus and Calculus course design can have a positive impact on student performance and academic achievement. In addition, cultivating a collaborative learning environment for both students and instructors is crucial. Our recommendation is aligned with what other research has suggested for best teaching practices (e.g. Wieman \& Gilbert, 2014; Wright, 2011; Bressoud et al, 2013). Subsequently, we encourage departments to utilize the curriculum mapping (Table 6) across the Precalculus to Calculus courses, as well as across different sections of the same course in order to promote consistency in promoting higher-order thinking and deep learning for students
\end{abstract}

\title{
Rethinking Assessments
}

Assessment and grading practices should be crafted to accurately capture student learning. In particular, students should be provided different opportunities to demonstrate their learning including: a) frequent inclass and take-home assignments that mirror high-stakes summative assessments; b) independent and group work tasks that help students develop higher-order thinking skills; c) alternative assessment methods such as projects and presentations to evaluate students' performance; and d) opportunities for revision of some graded assessments. To that end, standards-based, mastery-based, and project-based assessments could be incorporated into course design accordingly. Moreover, instructors should rethink traditional grading and assessment practices, especially post-COVID-19 era. Those alternative means could include digital formative assessments, self-reflection and self-assessments, and asynchronous collaborative tasks.

\section{Course Coordination and Professional Development (PD) Initiatives}

Mathematics content-specific professional development initiatives should be provided to instructors. Oftentimes, both full-time and part-time faculty are concerned about the time required for thoughtful course design and assessment methods that promote higher-order thinking for students. A designated course coordinator in addition to a professional learning community for instructors can help them be more effective with their instruction planning time and pedagogical approach. Due to a number of issues, including the ever-growing pressure on full-time faculty to intensify their research, it is becoming more challenging for them to be engaged in sustained and deep conversations around teaching and learning or to actively participate in course design and coordination. Our recommendation is that departments, with cooperation from the administration, should recognize the importance of course coordination and encourage both fulltime and part-time faculty to work closely with each other towards the common aim of delivering the best student-centered teaching practices.

\section{ACKNOWLEDGEMENT}

We would like to thank Ban Ang, Assistant Director/Systems Analyst in the Office of Provost at Montclair State University who helped us with the data collection.

\section{ENDNOTES}

1. We count grades below $70 \%$ as "Fail" because grades below this cutoff prevent students from taking subsequent courses.

2. Our decision to focus on Calculus I assessment reports was two-fold. First, the analysis of achievement data showing the significantly lower passing rates was of particular interest to us, especially considering the difference in coordination. Second, the assessment data for Calculus A was incomplete, thus making analyses less meaningful. 


\section{REFERENCES}

Bressoud, D.M., Carlson, M.P., Mesa, V., \& Rasmussen, C. (2013). The calculus student: Insights from the Mathematical Association of America national study. International Journal of Mathematical Education in Science and Technology, 44(5), 685-698.

Bressoud, D.M., Mesa, V., \& Rasmussen, C.L. (Eds.). (2015). Insights and recommendations from the MAA national study of college calculus. MAA Press.

Buch, K., McCullough, H., \& Tamberelli, L. (2017). Understanding and responding to the unique needs and challenges facing adjunct faculty: A longitudinal study. Int J Educ Res, 16(10), 27-40.

Burnstad, H. (2007). Best practices for supporting adjunct faculty. R.E. Lyons (Ed.). Anker Pub.

Carlson, M., Oehrtman, M., \& Moore, K. (2010). Precalculus: Pathways to calculus: A problem solving approach. Rational Reasoning.

Carnevale, A.P., Smith, N., \& Melton, M. (2011). STEM: Science Technology Engineering Mathematics. Georgetown University Center on Education and the Workforce.

Ellis, J., Kelton, M.L., \& Rasmussen, C. (2014). Student perceptions of pedagogy and associated persistence in calculus. ZDM, 46(4), 661-673.

Excel, E.T., \& Million, P.O. (2012). Report to the President.

Kimmel, K.M., \& Fairchild, J.L. (2017). A Full-Time Dilemma: Examining the Experiences of Part-Time Faculty. Journal of Effective Teaching, 17(1), 52-65.

Knight, P.T. (2002). Summative assessment in higher education: Practices in disarray. Studies in Higher Education, 27(3), 275-286.

Lattuca, L.R., \& Stark, J.S. (2009). Shaping the college curriculum: Academic plans in context (2nd ed.). San Francisco: Jossey-Bass.

OECD, D.S.E. (2019). Society at a Glance 2019. Organization for Economic.

Osborne, J., Simon, S., \& Collins, S. (2003). Attitudes towards science: A review of the literature and its implications. International Journal of Science Education, 25(9), 1049-1079.

Pampaka, M., Williams, J., Hutcheson, G., Wake, G., Black, L., Davis, P., \& Hernandez-Martinez, P. (2012). The association between mathematics pedagogy and learners' dispositions for university study. British Educational Research Journal, 38(3), 473-496.

Sjøberg, S., \& Schreiner, C. (2007). Perceptions and images of science and science education. In Communicating European Research 2005 (pp. 151-158). Springer, Dordrecht.

Seymour, E., \& Hewitt, N.M. (1997). Talking about leaving: Why undergraduates leave the sciences. Boulder, CO: Westview.

Team, R.C. (2017). R: A language and environment for statistical computing. R Foundation for Statistical Computing, Vienna, Austria. Retrieved from https://www.R-project.Org.

Thomas, B., \& Watters, J.J. (2015). Perspectives on Australian, Indian and Malaysian approaches to STEM education. International Journal of Educational Development, 45, 42-53.

White, N.J., \& Mesa, V. (2014). Describing cognitive orientation of calculus I tasks across different types of coursework. ZDM The International Journal on Mathematics Education. doi: $10.1007 / \mathrm{s} 1185801405889$.

Wieman, C., \& Gilbert, S. (2014). The teaching practices inventory: A new tool for characterizing college and university teaching in mathematics and science. CBE-Life Sciences Education, 13(3), 552569.

Wright, G.B. (2011). Student-centered learning in higher education. International Journal of Teaching and Learning in Higher Education, 23(1), 92-97. 